Ultra-Small Platinum Nanoparticles with High Catalytic Selectivity Synthesized by an Eco-friendly Method Supported on Natural Hydroxyapatite

S. A. Gama-Lara, R. Natividad, A. R. Vilchis-Nestor, Rafael LópezCastañares, I. García-Orozco, María G. Gonzalez-Pedroza, et al.

\section{Catalysis Letters}

ISSN 1011-372X

Catal Lett

DOI 10.1007/s10562-019-02919-Z
VOLUME 143 (2013)
No. 8

ISSN 1011-372X

Published August 2013

\section{CATA. FIRST}

LETTENS 
Your article is protected by copyright and all rights are held exclusively by Springer Science+Business Media, LLC, part of Springer Nature. This e-offprint is for personal use only and shall not be self-archived in electronic repositories. If you wish to selfarchive your article, please use the accepted manuscript version for posting on your own website. You may further deposit the accepted manuscript version in any repository, provided it is only made publicly available 12 months after official publication or later and provided acknowledgement is given to the original source of publication and a link is inserted to the published article on Springer's website. The link must be accompanied by the following text: "The final publication is available at link.springer.com". 


\title{
Ultra-Small Platinum Nanoparticles with High Catalytic Selectivity Synthesized by an Eco-friendly Method Supported on Natural Hydroxyapatite
}

\author{
S. A. Gama-Lara ${ }^{2} \cdot$ R. Natividad ${ }^{1} \cdot$ A. R. Vilchis-Nestor ${ }^{1} \cdot$ Rafael López-Castañares $^{3} \cdot$ I. García-Orozco $^{3}$. \\ María G. Gonzalez-Pedroza ${ }^{4} \cdot$ Raúl A. Morales-Luckie $^{1}$
}

Received: 8 May 2019 / Accepted: 19 July 2019

(c) Springer Science+Business Media, LLC, part of Springer Nature 2019

\begin{abstract}
The biosynthesis of Pt-nanoparticles (Pt NPs) supported on bovine bone powder was conducted by an environmentally friendly method that consists on immersing bovine bone powder into a $\mathrm{Pt}^{4+}$ metal ion solution at room temperature, atmospheric pressure and subsequent reduction by Heterotheca inuloides. It is worth pointing out that a calcination process is not required for the synthesis of this catalyst by the method reported herein. The nanocomposite was characterized by transmission electron microscopy (TEM), which revealed uniformly dispersed platinum nanoparticles with quasi-spherical form and average particle size of $7.1 \mathrm{~nm}$. The XPS studies exhibited the presence of $47.62 \% \mathrm{Pt}^{\circ}$ and $51.84 \% \mathrm{PtO}$. The catalyst activity was tested in the selective hydrogenation of 2-butyne-1,4-diol towards 2-butene-1,4-diol. The nanocomposite exhibits a reasonable catalytic performance with nearly $100 \%$ conversion of the alkyne and $96 \%$ selectivity towards 2-butene-1,4-diol.
\end{abstract}

\section{Graphic Abstract}

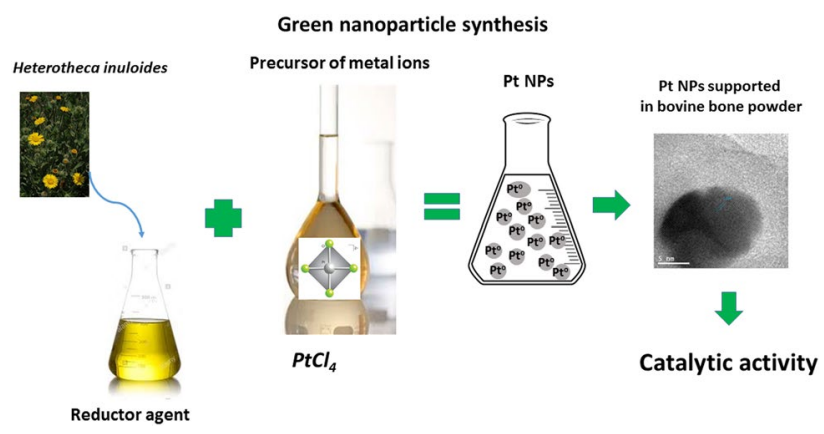

Keywords Platinum nanoparticles $\cdot$ Green nanosynthesis $\cdot$ Bionanotechnology $\cdot$ Heterotheca inuloides $\cdot$ Selective catalyst

\section{R. Natividad}

reynanr@gmail.com

$\triangle$ Raúl A. Morales-Luckie

ramluckie@gmail.com

1 Centro Conjunto de Investigación en Química Sustentable UAEM-UNAM, Universidad Autónoma del Estado de México, Carretera Toluca-Atlacomulco Km 14.5, San Cayetano, 50200 Toluca, Estado de México, Mexico

2 Universidad del Valle de México, De Las Palmas 439, San Jorge Pueblo Nuevo, 52164 Metepec, Estado de México, Mexico
3 Laboratorio de Investigación y Desarrollo de Materiales Avanzados Facultad de Química, Universidad Autónoma del Estado de México, A.P. A-20, 50120 Toluca, Mexico

4 Doctorado en Ciencia de Materiales de la Facultad de Química, Universidad Autónoma del Estado de México, Paseo Colón Esquina Paseo Tollocan S/N, C.P. 50000 Toluca, Estado de México, Mexico 


\section{Introduction}

In the last decades, the study of nanostructured systems has been conducted by different research groups. This is because such systems exhibit unique properties that allow them to be applied in different areas like catalysis, health care and others [1-4].

In the context of nanoparticles synthesis, special attention has been given to the use of environmentally friendly reagents and materials in order to increase the sustainability of the synthesis process [4]. Actually, it can be said that green chemistry is the goal of many researchers around the globe [1, 3-10]. It is of special interest the supports where nanoparticles are dispersed [5, 11-17]. Support materials such as silica [14], amorphous titania, cellulose [2], nylon, hexylamine and calcite $\left(\mathrm{CaCO}_{3}\right)$, among others, have been used [2, 11, 13]. The use of bio-supports such as cork [15], cotton $[11,16]$, bone [12] and shells, results in a relatively low-cost, renewable and environmentally friendly way of supporting metal nanoparticles [12-16]. For example, the one-step synthesis of platinum nanoparticles supported on wood has been reported. This was conducted by using hydroxyl groups $\left(\mathrm{OH}^{-}\right)$as reducing agent. The synthesized nanomaterial exhibited a high and relatively stable activity in the catalytic reduction of $p$-nitrophenol [17]. In the present investigation, bovine bone powder was used as support. This material is constituted by $60-70 \%$ hydroxyapatite $\left[\mathrm{Ca}_{10}\left(\mathrm{PO}_{4}\right)_{6}(\mathrm{OH})_{2}\right]$. This is advantageous since the $\mathrm{OH}^{-}$and $\mathrm{PO}_{4}{ }^{3-}$ groups work as binding sites for the metal nanoparticles. In addition, bovine bone powder is a low-cost, easy-to-treat, biodegradable and renewable material. Furthermore, hydroxyapatite importantly contributes to the mechanical strength, chemical stability at extreme $\mathrm{pH}$ and thermal stability of the synthesized composite. At the same time, hydroxyapatite works as a nanoreactor and provides of stability to nanoparticles, improving the catalytic effect.

Different methods (laser ablation or chemical methods) have been used to obtain metal nanoparticles. In this sense, several investigations have reported biological methods to reduce metal nanoparticles using bioreducers such as honey [18], saffron [19], tannins [20], nopal [21], caliandra [21], Camellia sinenses [22], fruits [23], chili, bacteria, alfalfa, among many others [4, 18, 19, 22-24]. In this sense, plant extracts containing bioactive particles such as alkaloids, phenolic acids, polyphenols, benzoic acid, coffeic acid and proteins, have been reported [11, $20,21,25-27]$ to play an important role in reducing and stabilizing metallic ions. It is also well known that the use of typical chemical methods leads to toxic products for both, environment and humans [4, 28]. On the other hand, the known advantages of biosynthesis or green synthesis are economic viability, environmentally friendly, easily scalable, and that can be performed at room temperature and atmospheric pressure. In this research, Heterotheca inuloides (Mexican arnica) was assessed as reducing agent to synthesize platinum nanoparticles on bovine bone in order to prove that this biosynthesis is low-cost, simple, friendly to the environment (the only used solvent is water and strong reducing agents are not required). In addition, the catalytic activity of the as-prepared material was assessed in the hydrogenation of 2-butyne-1,4-diol towards 2-butene-1,4-diol.

\section{Materials and Methods}

\subsection{Pt/Bovine Bone Biosynthesis}

The precursor compound of platinum nanoparticles was $\mathrm{PtCl}_{4}$. A $1 \mathrm{mM}$ solution was prepared with $50 \mathrm{~mL}$ of deionized water (solution 1). Solution 2 was prepared by boiling during $5 \mathrm{~min}$ in an Erlenmeyer flask, $1 \mathrm{~g}$ of dried $H$. inuloides with $100 \mathrm{~mL}$ of distilled water. In order to prepare the support, a bovine femur was washed, cleaned and immersed in a $0.01 \mathrm{M} \mathrm{HCl}$ solution. Later, the support was dried in an oven at $40{ }^{\circ} \mathrm{C}$ for $24 \mathrm{~h}$, then it was crushed and sieved by using a 170 mesh. $975 \mathrm{mg}$ of the so obtained powder was added to solution 1 and after $30 \mathrm{~s}$, the powder was filtered. The reduction of $\mathrm{Pt}(\mathrm{IV})$ ions was carried out with solution 2 during $1 \mathrm{~h}$ and then filtered. The resulting material was dried at room temperature overnight. Calcination is a common practice in the synthesis of heterogeneous catalysts, in this case, however, it is worth noticing that the synthesized composite was not calcined at any time. A micellar activity might also be expected since the micelle formation of sepia cartilage collagen solutions has been previously reported [29].

\subsection{Characterization}

Transmission electronic microscopy (TEM) and selected area electron diffraction (SAED) studies were carried out using a JEOL JEM-2100 microscope operating at $200 \mathrm{kV}$ accelerating voltage. The platinum-impregnated bovine bone powder was suspended in 2-propanol and then ultrasonically dispersed for $5 \mathrm{~h}$ at room temperature. A drop of this suspension was then placed on a Cu-grid coated with a holey carbon film. Also, the supported platinum nanoparticles were analyzed by SEM technique.

The X-ray photoelectronic spectroscopy (XPS) analysis was carried out in a JEOL JPS-9200 equipped with a $\mathrm{Mg}$ source $(1253.5 \mathrm{eV})$, operating at $200 \mathrm{~W}$ and vacuum of $1 \times 10^{-8}$ Torr. For all samples, the analysis area was $1 \mathrm{~mm}^{2}$. The specsurf ${ }^{\mathrm{TM}}$ software was used to analyze the results. 
Charge correction was done based on the adventitious carbon signal (C 1s) at $284.5 \mathrm{eV}$. Shirley method was used for background adjustment, whereas Gauss-Lorentz method was used for curve fitting.

\subsection{Hydrogenation of 2-Butyne-1,4-diol}

The hydrogenation of 2-butyne-1,4-diol was carried out in a $300 \mathrm{~mL}$ stainless-steel Parr reactor equipped with a temperature control system, a mechanical stirrer, pressure indicator, an inner heating/cooling coil system and sampling valve. A reservoir for $\mathrm{H}_{2}$ gas was used along with a constant pressure regulator to supply hydrogen at a constant pressure to the reactor.

In a typical hydrogenation experiment, $150 \mathrm{~mL}$ of $20 \%$ w/w aqueous 2-butyne-1,4-diol solution and $0.215 \mathrm{~g}$ of Ptsupported catalyst were loaded into the reactor. The initial concentration of the alkyne was $0.1 \mathrm{~mol} / \mathrm{L}$. The reactor was first flushed with nitrogen and then with hydrogen. After the desired temperature $(328 \mathrm{~K})$ was reached, the system was pressurized with hydrogen at the required pressure (6 bar) and a $550 \mathrm{rpm}$ stirring speed was set at all experiments. Samples were obtained every $30 \mathrm{~min}$.
Samples were analyzed by gas chromatography with a flame ionization detector using a 456 SCION GC (DBWAX 52 column, length $32 \mathrm{~m}$, inner diameter $=0.3 \mathrm{~mm}$ ) and helium ( $30 \mathrm{~mL} / \mathrm{min})$ as a carrier gas, according to previously reported analysis methods [30-33]. Reaction samples were injected into the GC and analyzed under the following conditions: temperature detector was set at $518 \mathrm{~K}$, injector temperature at $513 \mathrm{~K}$, the initial oven temperature was $353 \mathrm{~K}$ and this was raised up to $493 \mathrm{~K}$ at a rate of $10 \mathrm{~K} / \mathrm{min}$. This final oven temperature was kept constant for $3 \mathrm{~min}$.

\section{Results and Discussion}

\subsection{Characterization}

\subsubsection{Transmission Electron Microscopy (TEM) Analysis}

Figure 1a-c shows BF-STEM images where the platinum nanoparticles supported on bovine bone dust are clearly observed. The difference in electronic density allows to differentiate the platinum from the support that is constituted by hydroxyapatite (carbon, calcium, phosphorus and
Fig. 1 a-c BF-STEM images of Pt nanoparticles on bovine bone powder, at different magnifications, $\mathbf{d}$ size distribution of platinum nanoparticles
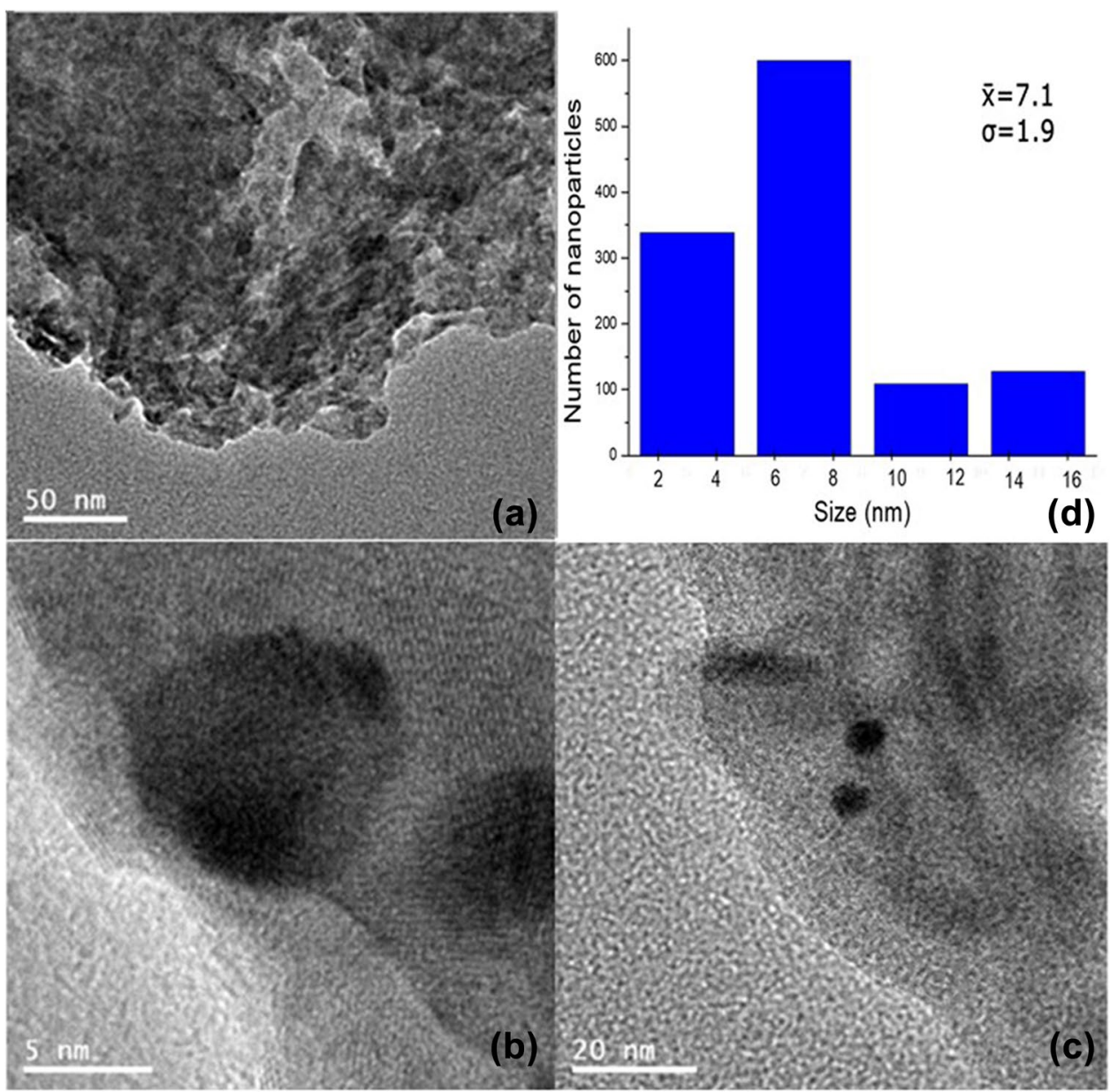
oxygen), BFSTEM shows metallic particles in a darker color. The particle size is in the range of 3 to $40 \mathrm{~nm}$, with few exemptions that are out of the particle size distribution. The images reveal that quasi-spherical Pt NPs with low size and low polydispersity are obtained into the bovine bone surface. These images correspond to a randomly chosen part of the substrate and can be considered as representative of the overall size and shapes of the particles.

These images correspond to Pt nanoparticles on the bovine bone powder after $5 \mathrm{~h}$ of ultrasonication. The average diameter of synthesized nanoparticles was found to be $7.1 \mathrm{~nm}$, taking into account 600 nanoparticles approximately (Fig. 1).

The use of bovine bone as catalytic support and $\mathrm{H}$. inuloides as reducer is rather novel. This synthesis method is relatively low-cost and environmentally friendly since the reducer and the support are easily biodegradable, the solvent is water and the calcination step followed by reduction with hydrogen is eliminated. Moreover, the chemical structure of hydroxyapatite can form stable compounds and anchor the metal ions.

Figure 2 shows two images of HRTEM where two particles of platinum supported on bovine bone powder can be observed, one of the platinum particles has an interplanar distance of $2.25 \AA$ which corresponds to the plane (111) for metallic platinum FCC. In the other micrograph, two interplanar distances are identified, one with $2.25 \AA$ that corresponds to the plane (111) of FCC metallic platinum (JCPDS card 00-004-0802) and the other with $2.66 \AA$ that corresponds to the plane (101) of tetragonal platinum oxide (JCPDS card 00-043-1100). Therefore, it can be concluded that the platinum nanoparticles are polycrystalline.

By observing the shape and chemical composition of nanoparticles, a fast reduction appears to rule the synthesis of platinum nanoparticles with $H$. inuloides as reducing agent since polycrystalline isotropic particles are obtained [34].
In addition, XPS was used to determine the oxidation state of the platinum nanoparticles. The narrow spectra in the $\mathrm{Pt}$ 4f region and its curve fitting, show two oxidation states for platinum (Fig. 3). The components at $70.9 \mathrm{eV}$ $(4 \mathrm{f} 7 / 2)$ and $74.4 \mathrm{eV}(4 \mathrm{f} 5 / 2)$ can be attributed to metallic platinum in around $47.62 \%$ of the total platinum, the energy separation of $4 \mathrm{f} 7 / 2$ and $4 \mathrm{f} 5 / 2$ is $3.5 \mathrm{eV}$ corresponding to that reported for platinum, the ratio proportion intensity of the orbitals $4 \mathrm{f} 7 / 2$ with respect to $4 \mathrm{f} 5 / 2$ is $4: 3$ as it could be corroborated. The signals at $72.5 \mathrm{eV}(4 \mathrm{f} 7 / 2)$ and $76.7 \mathrm{eV}$ (4f5/2) correspond to $51.84 \%$ of the total platinum and can be ascribed to platinum oxide. The energy separation of $4 \mathrm{f} 7 / 2$ and $4 \mathrm{f} 5 / 2$ is $3.1 \mathrm{eV}$ corresponding to that reported for platinum, the ratio proportion intensity of the orbitals $4 f 7 / 2$ with respect to $4 f 5 / 2$ is $4: 3$ as it could be corroborated.

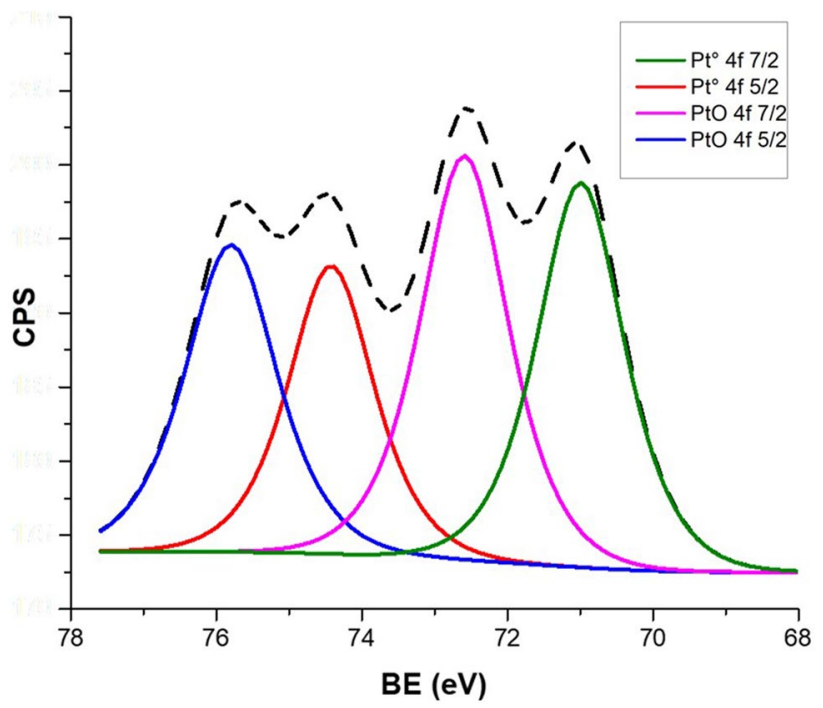

Fig. 3 XPS spectra corresponding to the $4 \mathrm{f} 5 / 2$ (pink line) and $\mathrm{Pt}$ $4 \mathrm{f} 7 / 2$ (dark green line) regions of the platinum nanoparticles supported on bovine bone dust
Fig. 2 HRTEM micrograph Ptnanobiocomposite

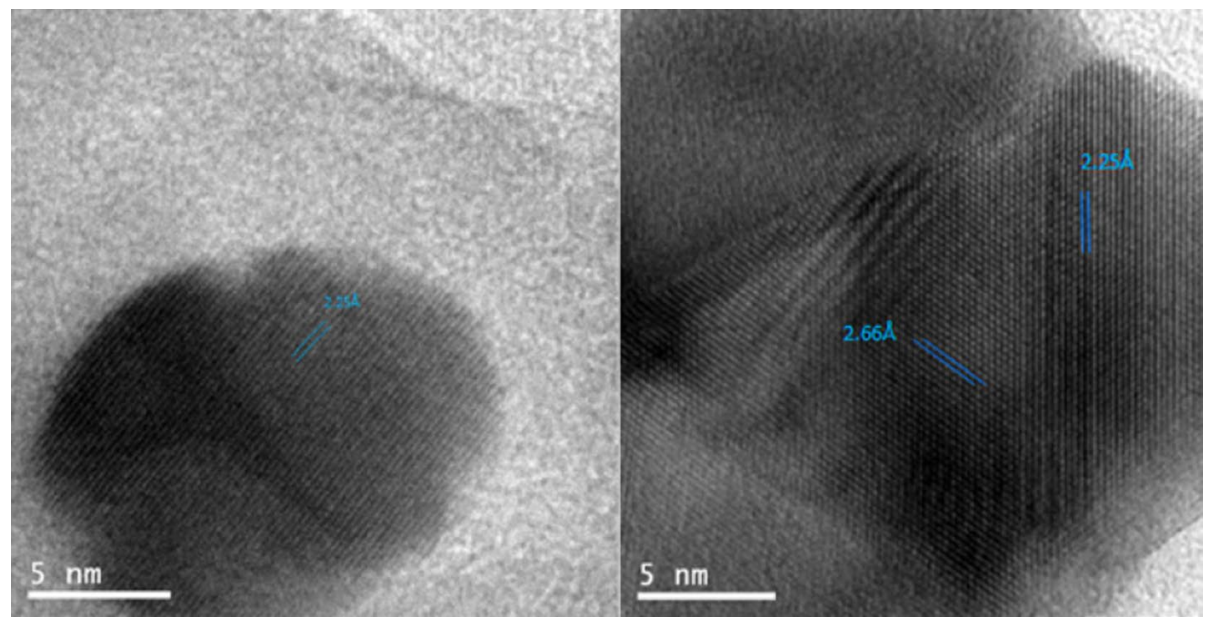


These results indicate that the reduction of $\mathrm{Pt}(\mathrm{IV})$ to $\mathrm{Pt}^{\circ}$ indeed took place and that Pt nanoparticles were supported onto the bovine bond powder in controlled size and shape.

\subsection{Catalytic Activity}

The catalytic activity of the synthesized powder was established in the hydrogenation of 2-butyne-1,4-diol. This reaction has been reported to be catalyzed by metallic Pt or Pd $[32,33,35]$. Therefore, the exhibited catalytic activity can be taken as an additional proof of the presence of metallic nanoparticles obtained by employing the bio-reducer $H$. inuloides. Nevertheless, the XPS results shows the presence of oxidized Pt and the catalytic contribution of this specie should not be discarded [36]. The referenced reaction has been reported to proceed as depicted in Scheme 1. According to this scheme, the consumption of the first hydrogen mole leads to the production of the usually desired intermediary, 2-butene-1,4-diol. The further consumption of $\mathrm{H}_{2}$ produces the saturated diol (butanediol) and by-products like crotyl alcohol and/or butanol. Thus, in the context of this reaction, achieving a high selectivity towards 2-butene-1,4diol, represents a challenge that has been usually addressed by adding chemical bases or by modifying the reactor hydrodynamics [32]. Figure 4 is the evidence that the synthesized material not only exhibits catalytic activity but also a high selectivity (0.96) towards the alkene.

The kinetics of the 2-butyne-1,4-diol hydrogenation was established by the integral method. A linear relationship between 2-butyne-1,4-diol concentration and reaction time was found when plotting the former versus the latter. By doing this, the specific rate constant was found to be $k_{o}=0.001 \mathrm{~mol} / \mathrm{dm}^{3} \mathrm{~min}$. Thus, it can be concluded that under the studied conditions, the hydrogenation rate is independent of the alkyne concentration (zero order reaction regarding 2-butyne-1,4-diol). This reaction has been reported to follow a Langmuir-Hinshelwood mechanism when using $\mathrm{Pd}$ as active phase [32, 33, 37].

This mechanism suggests that both $\mathrm{H}_{2}$ and the alkyne, are chemisorbed and compete for the same type of sites. It has been demonstrated [32] though, that the alkyne chemisorbs stronger than hydrogen and that olefins. This implies that the adsorption equilibrium constant for the alkyne is much higher than that of the other compounds. Therefore, the adsorption of hydrogen and the products can be neglected

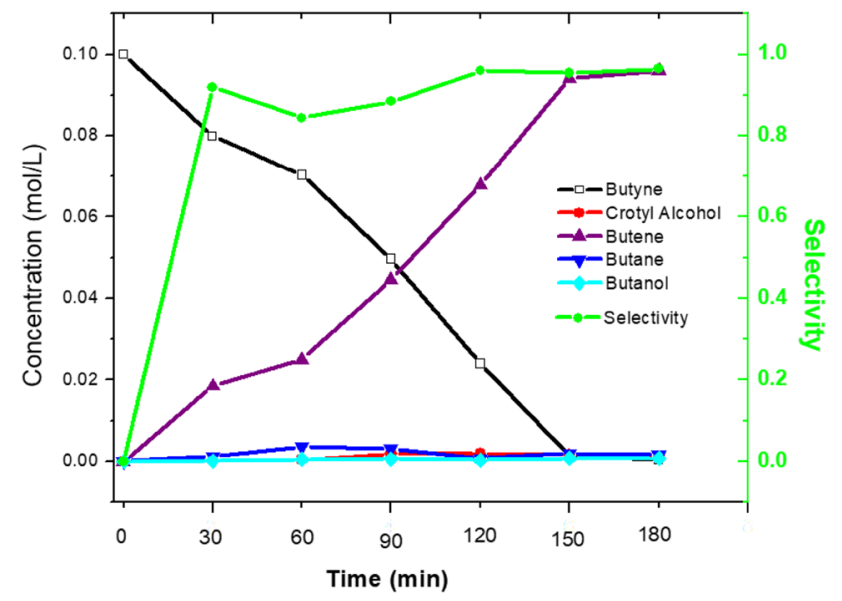

Fig. 4 Concentration and selectivity profiles for the hydrogenation of 2-butyne-1,4-diol. Reaction conditions: temperature, $328 \mathrm{~K}$; pressure, 6 bar; initial concentration, $20 \%$ aqueous solution of 2-butyne-1,4diol; active concentration of the catalyst, $0.215 \mathrm{mg}$; stirring speed, $550 \mathrm{rpm}$; total volume, $1.5 \times 10^{-4} \mathrm{~m}^{3}$

when the surface coverage by the alkyne is relatively high. This results in the zero-order kinetic equation regarding 2-butyne-1,4-diol [37].

Finally, it is worth noticing that the synthesized catalyst consisting on platinum nanoparticles supported on bovine bone powder, eliminates the use of base addition to obtain a selectivity above $90 \%$ in the hydrogenation of 2-butyne-1,4diol. For the same reaction, Telkar et al. indicate that with $1 \% \mathrm{Pt} / \mathrm{CaCO}_{3}$ they obtained a selectivity of $83 \%$ and when adding ammonia in the hydrogenation reaction, $100 \%$ selectivity is obtained [35]. This suggests that the attained high selectivity in this work might be ascribed to an enhanced basicity of the biosynthesized catalyst. A heterogeneous catalyst selectivity, however, might be influenced by other factors like particle size and shape [38]. In this case, as we are dealing with nanoparticles, it is very likely that the observed high selectivity might also be related to the average nanoparticle size $(7.1 \mathrm{~nm})$. In this regard, it has been demonstrated [38] that nanoparticle size might change the activation energy of a specific reaction and thus selectivity. In the same work [38], it was shown that platinum nanoparticles shape (cubes or cuboctahedra) leads to complete different products distribution in the hydrogenation of benzene. Therefore, the fact of having obtained semi-spherical
Scheme 1 2-butyne-1,4-diol hydrogenation scheme [33]. A: 2-butyne-1,4-diol, B: 2-butene1,4-diol, C: butane-1,4-diol, D: crotyl alcohol, E: n-butanol

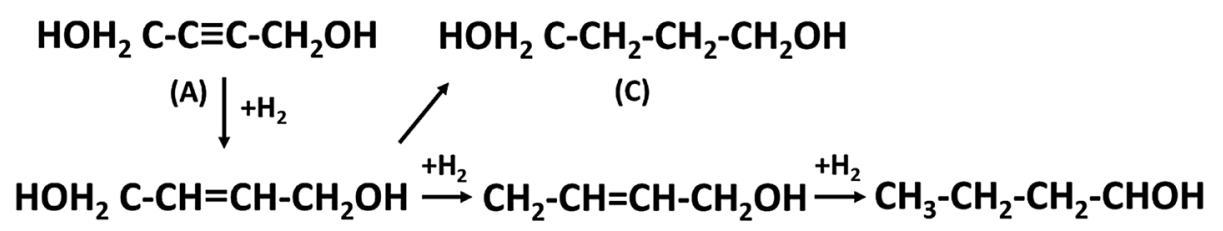

(B)

(D)

(E) 
Pt nanoparticles in this work, might also be influencing the selectivity towards the alkene. At the end, it can be said that the observed high selectivity is the result of the combined effect of support, Pt nanoparticle size and shape. A special research work should be dedicated to establishing which of these factors affects selectivity the most.

\section{Conclusions}

Metallic platinum nanoparticles supported on bovine bone powder were synthesized by using as reducing agent $H$. inuloides (Mexican arnica). The average diameter of synthesized nanoparticles was found to be $7.1 \mathrm{~nm}$. The resulting bio-nanocomposite exhibits catalytic activity to conduct hydrogenation reactions with high selectivity (96.5\%) towards the intermediary in a consecutive hydrogenation reaction.

In addition, it can also be concluded that bovine bone powder is an efficient, low-cost support of platinum nanoparticles.

This synthesis method presented here is relatively lowcost and environmentally friendly since the support is a waste material, the solvent is water, the calcination step is eliminated and the reducing agent is environmentally friendly.

Acknowledgements We thank Dr. Gustavo López-Téllez (CCIQS, Universidad Autónoma del Estado de México) for assistance in XPS studies and Citlalit Martínez for technical support. S.A. Gama-Lara acknowledges CONACYT financial support to conduct postgraduate studies. CONACYT Project 269093 is also acknowledged.

\section{Compliance with Ethical Standards}

Conflict of interest The authors declare no conflict of interest.

\section{References}

1. Bae SW, Tan W, Hong J-I (2012) Fluorescent dye-doped silica nanoparticles: new tools for bioapplications. Chem Commun 48(17):2270-2282

2. He J, Kunitake T, Nakao A (2003) Facile in situ synthesis of noble metal nanoparticles in porous cellulose fibers. Chem Mater 15(23):4401-4406

3. Jiang Z, Xie J, Jiang D, Wei X, Chen M (2013) Modifiers-assisted formation of nickel nanoparticles and their catalytic application to p-nitrophenol reduction. CrystEngComm 15(3):560-569

4. Shah M, Fawcett D, Sharma S, Tripathy S, Poinern G (2015) Green synthesis of metallic nanoparticles via biological entities. Materials 8(11):7278-7308

5. Tang F, Li L, Chen D (2012) Mesoporous silica nanoparticles: synthesis, biocompatibility and drug delivery. Adv Mater 24(12):1504-1534

6. Wang F, Wang Y-C, Dou S, Xiong M-H, Sun T-M, Wang J (2011) Doxorubicin-tethered responsive gold nanoparticles facilitate intracellular drug delivery for overcoming multidrug resistance in cancer cells. ACS Nano 5(5):3679-3692

7. Zhang W, Lu G, Cui C, Liu Y, Li S, Yan W et al (2014) A family of metal-organic frameworks exhibiting size-selective catalysis with encapsulated noble-metal nanoparticles. Adv Mater 26(24):4056-4060

8. Zhao X, Tapec-Dytioco R, Tan W (2003) Ultrasensitive DNA detection using highly fluorescent bioconjugated nanoparticles. J Am Chem Soc 125(38):11474-11475

9. Li P-Z, Aranishi K, Xu Q (2012) ZIF-8 immobilized nickel nanoparticles: highly effective catalysts for hydrogen generation from hydrolysis of ammonia borane. Chem Commun 48(26):3173-3175

10. Linse S, Cabaleiro-Lago C, Xue W-F, Lynch I, Lindman S, Thulin E et al (2007) Nucleation of protein fibrillation by nanoparticles. Proc Natl Acad Sci 104(21):8691-8696

11. López Iturbe J, Vilchis Nestor AR, Sánchez Mendieta V, Avalos Borja M (2013) Obtención y caracterización de nanopartículas de plata soportadas en fibra de algodón. Superf y vacío 26(3):73-78

12. Becerril-Juárez IG, Morales-Luckie RA, Ureña-Nuñez F, ArenasAlatorre JA, Hinestroza JP, Sánchez-Mendieta V (2012) Silver micro-, submicro-and nano-crystals using bovine bone as template. Formation of a silver/bovine bone composite. Mater Lett 85:157-160

13. Darder M, Aranda P, Ruiz-Hitzky E (2007) Bionanocomposites: a new concept of ecological, bioinspired, and functional hybrid materials. Adv Mater 19(10):1309-1319

14. Veith GM, Lupini AR, Rashkeev S, Pennycook SJ, Mullins DR, Schwartz V et al (2009) Thermal stability and catalytic activity of gold nanoparticles supported on silica. J Catal 262(1):92-101

15. Francesko A, Blandón L, Vázquez M, Petkova P, Morató J, Pfeifer A et al (2015) Enzymatic functionalization of cork surface with antimicrobial hybrid biopolymer/silver nanoparticles. ACS Appl Mater Interfaces 7(18):9792-9799

16. Ravindra S, Mohan YM, Reddy NN, Raju KM (2010) Fabrication of antibacterial cotton fibres loaded with silver nanoparticles via "Green Approach". Colloids Surf A 367(1-3):31-40

17. Lin X, Wu M, Wu D, Kuga S, Endo T, Huang Y (2011) Platinum nanoparticles using wood nanomaterials: eco-friendly synthesis, shape control and catalytic activity for p-nitrophenol reduction. Green Chem 13(2):283-287

18. Balasooriya ER, Jayasinghe CD, Jayawardena UA, Ruwanthika RWD, Mendis de Silva R, Udagama PV (2017) Honey mediated green synthesis of nanoparticles: new era of safe nanotechnology. J Nanomater 2017:10

19. Bagherzade G, Tavakoli MM, Namaei MH (2017) Green synthesis of silver nanoparticles using aqueous extract of saffron (Crocus sativus $\mathrm{L}$.) wastages and its antibacterial activity against six bacteria. Asian Pac J Trop Biomed 7(3):227-233

20. Raja PB, Rahim AA, Qureshi AK, Awang K (2014) Green synthesis of silver nanoparticles using tannins. Mater Sci-Pol 32(3):408-413

21. Silva-de-Hoyos L, Sánchez-Mendieta V, Rico-Moctezuma A, Vilchis-Nestor A, Camacho-López M, Avalos-Borja M (2012) Silver nanoparticles biosynthesized using Opuntia ficus aqueous extract. Superf y vacío 25(1):31-35

22. Rengga WDP, Yufitasari A, Adi W (2017) Synthesis of silver nanoparticles from silver nitrate solution using green tea extract (Camelia sinensis) as bioreductor. Jurnal Bahan Alam Terbarukan 6(1):32-38

23. Kumar B, Smita K, Cumbal L, Debut A (2017) Green synthesis of silver nanoparticles using Andean blackberry fruit extract. Saudi J Biol Sci 24(1):45-50

24. Raja S, Ramesh V, Thivaharan V (2017) Green biosynthesis of silver nanoparticles using Calliandra haematocephala leaf extract, their antibacterial activity and hydrogen peroxide sensing capability. Arab J Chem 10(2):253-261 
25. Almajano MP, Carbo R, Jiménez JAL, Gordon MH (2008) Antioxidant and antimicrobial activities of tea infusions. Food Chem 108(1):55-63

26. Teimuri-Mofrad R, Hadi R, Tahmasebi B, Farhoudian S, Mehravar M, Nasiri R (2017) Green synthesis of gold nanoparticles using plant extract: mini-review. Nanochem Res 2(1):8-19

27. Gama-Lara SA, Morales-Luckie R, Argueta-Figueroa L, Hinestroza JP, García-Orozco I, Natividad R (2018) Synthesis, characterization, and catalytic activity of platinum nanoparticles on bovine-bone powder: a novel support. J Nanomater 2018:8

28. Abdelrazek EM, Abdelghany AM, Badr SI, Morsi MA (2018) Structural, optical, morphological and thermal properties of $\mathrm{PEO} /$ PVP blend containing different concentrations of biosynthesized Au nanoparticles. J Mater Res Technol 7(4):419-431

29. Mandal AB, Ramesh DV, Dhar SC (1987) Physico-chemical studies of micelle formation on sepia cartilage collagen solutions in acetate buffer and its interaction with ionic and nonionic micelles: hydrodynamic and thermodynamic studies. Eur J Biochem 169(3):617-628

30. Tanielyan SK, More SR, Augustine RL, Schmidt SR (2017) Continuous liquid-phase hydrogenation of 1, 4-butynediol to highpurity 1, 4-butanediol over particulate raney nickel catalyst in a fixed bed reactor. Org Process Res Dev 21(3):327-335

31. Duncanson IT, Sutherland IW, Cullen B, Jackson SD, Lennon D (2005) The hydrogenation of 2-butyne-1, 4-diol over a carbonsupported palladium catalyst. Catal Lett 103(3-4):195-199

32. Natividad R, Kulkarni R, Nuithitikul K, Raymahasay S, Wood J, Winterbottom J (2004) Analysis of the performance of single capillary and multiple capillary (monolith) reactors for the multiphase
Pd-catalyzed hydrogenation of 2-butyne-1, 4-diol. Chem Eng Sci 59(22-23):5431-5438

33. Fishwick RP, Natividad R, Kulkarni R, McGuire PA, Wood J, Winterbottom JM et al (2007) Selective hydrogenation reactions: a comparative study of monolith CDC, stirred tank and trickle bed reactors. Catal Today 128(1-2):108-114

34. Suber L, Sondi I, Matijević E, Goia DV (2005) Preparation and the mechanisms of formation of silver particles of different morphologies in homogeneous solutions. J Colloid Interface Sci 288(2):489-495

35. Telkar M, Rode C, Jaganathan R, Rane V, Chaudhari R (2002) Platinum catalyzed hydrogenation of 2-butyne-1, 4-diol. J Mol Catal A 187(1):81-93

36. Park JY, Aliaga C, Russell Renzas J, Lee H, Somorjai GA (2009) The role of organic capping layers of platinum nanoparticles in catalytic activity of CO oxidation. Catal Lett 129:1-6

37. Joannet E, Horny C, Kiwi-Minsker L, Renken A (2002) Palladium supported on filamentous active carbon as effective catalyst for liquid phase hydrogenation of 2-butyne-1,4-diol to 2-butene-1,4diol. Chem Eng Sci 57:3453-3460

38. Somorjai GA, Park JY (2008) Molecular factors of catalytic selectivity. Angew Chem Int Ed 47:9212-9228

Publisher's Note Springer Nature remains neutral with regard to jurisdictional claims in published maps and institutional affiliations. 